\title{
MODIFIED MULTI-LAYERED MODEL OF TEMPERATURE DEPENDENT MOTOR NERVE AXONS
}

\author{
Diana Stephanova ${ }^{1}$, Mariya Daskalova ${ }^{1}$, Stefan Krustev ${ }^{2}$ \\ ${ }^{1}$ Institute of Biophysics and Biomedical Engineering, Bulgarian Academy of Sciences, Sofia \\ and ${ }^{2}$ Department of Medical Physics and Biophysics, Faculty of Pharmacy, \\ Medical University of Varna
}

\begin{abstract}
PURPOSE: Extensive sets of simulations are realized in this paper to gain insight into the problems of impulse propagation in temperature dependent motor nerve axons. The effect of temperature on the impulse threshold currents and action potential parameters (velocity, amplitude) is shown in simulated mammalian (rabbit) and human motor nerve fibres.

MATERIAL AND METHODS: Using our multi-layered model of human motor nerve fibre, temperature coefficients $Q_{10}$ 's are involved for the conductivities of axoplasm, periaxonal space and for ionic currents (nodal and intermodal). The standard temperature for our model is $37^{\circ} \mathrm{C}$. The temperature increases from 20 to $60^{\circ} \mathrm{C}$.

RESULTS: The essential and very important result is that the simulated conduction block at 48 and $45^{\circ} \mathrm{C}$ in the rabbit and human motor nerve axons, respectively, is extremely sensitive to the rate constants of nodal sodium $\left(\mathrm{P}_{\mathrm{Na}}\right)$, fast potassium $\left(\mathrm{P}_{\mathrm{Kf}}\right)$ and slow $\left(\mathrm{P}_{\mathrm{Ks}}\right)$ potassium maximum permeabilities. The temperature dependence of conduction velocity over a range of $20-42^{\circ} \mathrm{C}$ and $20-40^{\circ} \mathrm{C}$ for the rabbit and human motor nerve axons, respectively, is not linear or exponential. Due to this, a polynomial function of degree 2 (transfer standard parabola), which relates velocity to temperature, provides an accurate fit of the data.

CONCLUSION: Our modified multi-layered model used in this study is first ever in which the simulated temperature dependent velocities and conduction block in the rabbit and human motor axons are in good agreement with the experimental values.
\end{abstract}

Key words: temperature, action potential parameters, motor axons, temperature dependent multi-layered model, computational neuroscience

Address for correspondence:

Diana Stephanova, DSc

Institute of Biophysics and Biomedical Engineering,

Bulgarian Academy of Sciences,

Acad. G. Bontchev Str., Bl. 21, 1113 Sofia, Bulgaria

e-mail:dsteph@bio.bas.bg

Received: May 27, 2013

Accepted: July 30, 2013

\section{INTRODUCTION}

Experimentally, it is clear that the axonal conduction velocity increases with temperature in the physiological range of $29-38^{\circ} \mathrm{C}(1,4,5,10,14,17)$, whereas the amplitude of nerve and muscle action potentials slightly decreases $(2,3,16)$. The effect of temperature on the conduction block was also investigated and discussed $(9,19)$.

Computations made for myelinated nerve fibres suffer from several defects. First, the temperature coefficients of the appropriate parameters for 
mammalian nerve fibres either are unknown or at best are known only for a small range of temperature near room temperature $(6,7,11-13,15,18,20,23,24)$. Second, there are conflicting results of simulations, on showing linear or exponential dependence of the velocity on temperature $(12,13,18,27)$. Third, the models cited above except for the model of $(23,24)$ do not simulate the conduction block of myelinated nerve axons. Moreover all models are one cable and are based on the equations of Hodgkin-Huxley $(6,18)$ or Frankenhaeuser-Huxley $(7,11-13,15,23,24)$. The standard temperature is $6.3^{\circ} \mathrm{C}$ for Hodgkin-Huxley models, whereas it is $20^{\circ} \mathrm{C}$ for FrankenhaeuserHuxley models. Finally, some values of the conduction velocity agree with experimental values while others disagree by a factor as large as two.

The aim of this study is to modify the already existing our model of human motor nerve fiber (25) and to achieve values of the temperature dependent action potential parameters in reasonable agreement with the experimental data.

\section{MATERIAL AND METHODS}

The computations use our multi-layered model of human motor nerve fibre (25), in which the complex myelin sheath structure of 150 interconnected parallel lamellae is simulated by alternating 150 lipid and 150 aqueous layers. This model is also thoroughly described in (26). All calculations in the normal and modified model are carried out for fibres with: an axon diameter of $12.5 \mu \mathrm{m}$; an external fibre diameter of $17.3 \mu \mathrm{m}$; nodal diameter of $5 \mu \mathrm{m}$; nodal area of $24 \mu \mathrm{m}^{2}$; myelin thickness of $2.4 \mu \mathrm{m}$; periodicity of myelin lamellae of $16 \mathrm{~nm}$ and periaxonal space thickness of $20 \mathrm{~nm}$. The standard temperature is $37^{\circ} \mathrm{C}$.

Extensive sets of simulations are realized in this paper as the quantitative change in conduction velocity with temperature depends on which temperature-sensitive parameters are included. Temperature coefficients $\left(\mathrm{Q}_{10}{ }^{\mathrm{s}}\right)$ are involved in the used here model in order to determine the dependence of conduction parameters on the temperature. The equations in which the temperature coefficients enter explicitly are: $\mathrm{Q}_{10}{ }^{\mathrm{s}}=\mathrm{Q}_{10}{ }^{(\mathrm{ts}-37.0) / 10}$, where $\mathrm{t}_{\mathrm{s}}$ are temperatures $\left({ }^{\circ} \mathrm{C}\right) . \mathrm{T}_{\mathrm{s}}=\left(273.16^{\circ} \mathrm{C}+\mathrm{t}_{\mathrm{s}}\right)$, where $\mathrm{T}_{\mathrm{s}}$ are temperatures $(\mathrm{K})$. In the case when $\mathrm{t}$ equals $37^{\circ} \mathrm{C}$, the system of equations presented in the normal model $(25,26)$ is realized. The action potential stimulation in the normal and modified model is simulated by adding a short $(0.1 \mathrm{~ms})$ rectangular depolarizing current pulse to the center of the first node. This case of point application of current intra-axonally at the node closely approximates the effects of point application of current extra-axonally at the node and realizes a point fibre polarization.

\section{RESULTS}

In the first set of simulations, the rate constants are modified using the following $\mathrm{Q}_{10}$ values: 2.2 for $a_{m}, b_{m}(21,22) ; 2.9$ for $a_{h}, b_{h}(21,22) ; 3.0$ for $a_{n}, b_{n}(8,22)$; 3.0 for $a_{s}, b_{s}(22)$. The maximum permeabilities of $\operatorname{sodium}\left(\mathrm{P}_{\mathrm{Na}}\right)$, fast potassium $\left(\mathrm{P}_{\mathrm{Kf}}\right)$ and slow potassium $\left(\mathrm{P}_{\mathrm{Ks}}\right)$ nodal channels are modified using the following $\mathrm{Q}_{10}$ values: 1.3 for $\mathrm{P}_{\mathrm{Na}}(8,20,22,24) ; 1.2$ for $\mathrm{P}_{\mathrm{KP}} \mathrm{P}_{\mathrm{Ks}}$ $(8,20,23,24)$. The $\mathrm{Q}_{10}$ is 1.25 (18) for the conductance of axoplasm $\left(1 / R_{a x}\right)$. The same $Q_{10}$ value is included in the model for the conductance $\left(1 / \mathrm{R}_{\mathrm{pa}}\right)$ of periaxonal space. Electrolytes show a temperature increase in conductance with a $\mathrm{Q}_{10}$ of 1.25 to 1.3. The axoplasm and periaxonal conductivities are electrolytic and should be given similar temperature dependence. For this temperature dependent modified model, a conduction block of impulse propagation is not achieved when the temperature increases from $20^{\circ} \mathrm{C}$ to an extremely high value of $100^{\circ} \mathrm{C}$.

In the second set of simulations, the temperature increases from 20 to $60^{\circ} \mathrm{C}$. And the $\mathrm{Q}_{10}$ 's are changed in such a way, that conduction blocks to be achieved at 60,48 and $45^{\circ} \mathrm{C}$. Surprisingly, for temperatures higher than $37^{\circ} \mathrm{C}$, the axonal conduction block was found to be quite sensitive to the maximum permeabilities of the nodal channels. And they are modified using the following $\mathrm{Q}_{10}$ values: (i) 2.4 for $\mathrm{P}_{\mathrm{Na}}$ and 5.9 for $\mathrm{P}_{\mathrm{KP}} \mathrm{P}_{\mathrm{Ks}}$ in the case of conduction block at $60^{\circ} \mathrm{C}$; (ii) 3.5 for $\mathrm{P}_{\mathrm{Na}}$ and 50.0 for $\mathrm{P}_{\mathrm{Kf}}, \mathrm{P}_{\mathrm{Ks}}$ in the case of conduction block at $48^{\circ} \mathrm{C}$; and (iii) 4.0 for $\mathrm{P}_{\mathrm{Na}}, 220.0$ for $\mathrm{P}_{\mathrm{KP}} \mathrm{P}_{\mathrm{Ks}}$, and 2.7 for $\mathrm{a}_{\mathrm{m}}, \mathrm{b}_{\mathrm{m}}$ in the case of conduction block at $45^{\circ} \mathrm{C}$. For the three (i-iii) cases at temperatures lower than $37^{\circ} \mathrm{C}$, the $\mathrm{Q}_{10}{ }^{\text {'s }}$ values of the maximum permeabilities are equal and are the same as those involved in the (i) case, i.e. 2.4 for $\mathrm{P}_{\mathrm{Na}}$ and 5.9 for $\mathrm{P}_{\mathrm{KP}} \mathrm{P}_{\mathrm{Ks}}$. The remaining $\mathrm{Q}_{10}{ }^{\text {'s }}$ values given above in the first investigated set of simulations are unchanged. The temperature dependence of action potential parameters [velocity 

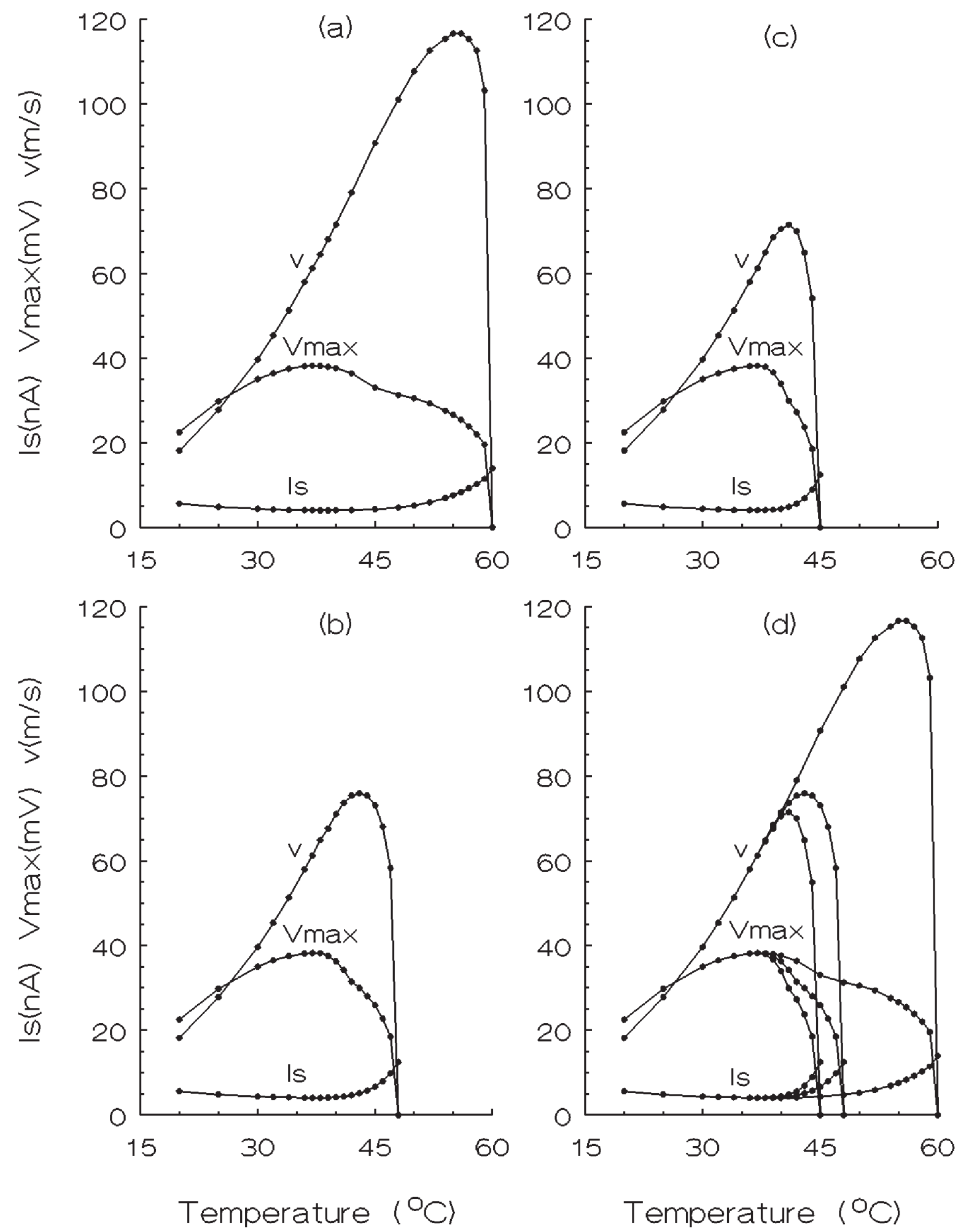

Fig. 1. Effect of temperature on the conduction velocity (v), action potential amplitude (Vmax) and impulse threshold current (Is) of motor nerve axons in the cases of conduction block at $60^{\circ} \mathrm{C}(\mathrm{a}) ; 48^{\circ} \mathrm{C}(\mathrm{b}) ; 45^{\circ} \mathrm{C}(\mathrm{c})$. And the results from (ac) are given together (d). Note that the $y$-scales of $v$, Vmax and Is are equal and overlapped, but they are with different dimensions in the a-d panel figures 

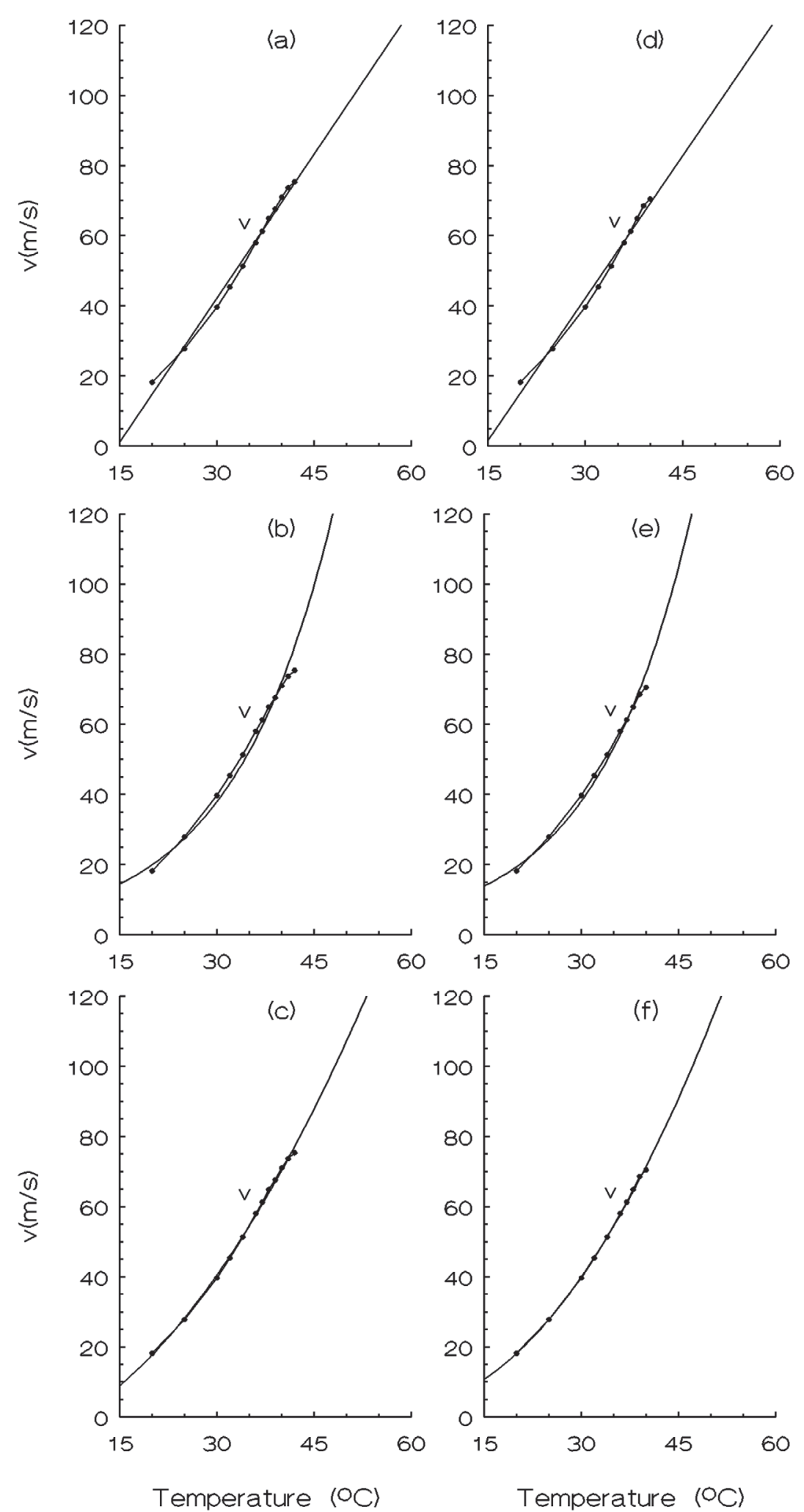

Fig. 2. Temperature dependence of the conduction velocity over a range of $20-42^{\circ} \mathrm{C}(\mathrm{a}-\mathrm{c})$ and $20-40^{\circ} \mathrm{C}(\mathrm{d}-\mathrm{f})$ for the rabbit and human motor nerve axons, respectively. The curves are fitted by linear $(a, d)$, exponential $(b, e)$ functions and polynomial function of degree $2(c, f)$ 
(v), amplitude (Vmax)] and impulse threshold current (Is) is investigated and shown in Fig. 1. To provide a better illustration these parameters are presented together in the panel figures where the parameter's $y$-scales are equal and overlapped, but they are with different dimensions. The conduction block that actually is observed in real myelinated nerve (at about $48^{\circ} \mathrm{C}$ in the rabbit and $45^{\circ} \mathrm{C}$ in the human) is in good agreement with our simulations (see v curves in Fig. 1b,c, respectively). An unrealistic case is given in Fig. 1a and all investigated cases are compared in Fig. 1d. The conduction velocities calculated from the times of the potential maxima at the nodes increase from 18.18 to $71.50 \mathrm{~m} / \mathrm{sec}$ (in the human axon) and from 18.18 to $75.47 \mathrm{~m} / \mathrm{sec}$ (in the rabbit axon) and then rapidly decrease achieving the blocking value. The potential amplitudes increase up to given temperature and then decrease with the increase of temperature. Conversely, the impulse threshold currents decrease up to given temperature and then increase with the increase of temperature. The results show that the temperature dependence of conduction velocity over a range of $20-42^{\circ} \mathrm{C}$ and 20 $40^{\circ} \mathrm{C}$ for the rabbit (Fig. 2a-c) and human (Fig. 2df) motor axons, respectively, is not linear (Fig. 2a,d) or exponential (Fig. 2b,e). Due to this, a polynomial function of degree 2 (transfer standard parabola), which relates velocity to temperature, provides an accurate fit of the data for the rabbit and human axons (Fig. 2c,f).

\section{DISCUSSION}

A modified multi-layered model describing the behavior of motor nerve axons in the range of $10-60^{\circ} \mathrm{C}$ is suggested. The present study compares the effects of temperature on different conduction parameters of rabbit and human motor axons. For temperatures lower than $37^{\circ} \mathrm{C}$, the conduction parameters $(v$, Vmax, Is) are equal in the rabbit and human motor axons. The conduction velocity of $18.18 \mathrm{~m} / \mathrm{sec}$ at $20^{\circ} \mathrm{C}$ is the same as the calculated by $(11,13,15)$. The conduction velocity increases by $\sim 5 \%$ per degree $\mathrm{C}$ as the temperature increases from 28 to $38^{\circ} \mathrm{C}$. The same values are characteristic for human nerve $(4,14,17)$. The conduction block at about $48^{\circ} \mathrm{C}$ experimentally observed in the rabbit (19) is correctly reproduced in the model. The simulated conduction block at $45^{\circ} \mathrm{C}$ in the human motor axon is in agreement with our previous investigation (23).

\section{CONCLUSION}

In summary, our modified multi-layered model used in this study is first ever in which the simulated temperature dependent velocities and conduction block in the rabbit and human motor axons are in good agreement with the experimental values. The results are important for the interpretation of excitability measurements from patients with peripheral nerve disorders and for deciding the best strategy to adopt when testing control groups and patients with different limb temperatures.

\section{REFERENCES}

1. Bolton, C. F., K. Carter, J. J. Koval. Temperature effects on conduction studies of normal and abnormal nerve.- Muscle Nerve, 5, 1982, Suppl. 9, S145-S147.

2. Bolton, C. F., G. M. Sawa, K. Carter. The effect of temperature on human compound action potentials.- J. Neurol. Neurosurg. Psychiatry, 44, 1981, No 5, 407-413.

3. Buchthal, F., A. Rosenfalck. Evoked action potentials and conduction velocity in human sensory nerves.- Brain Res., 3, 1966, No 1, 1-122.

4. De Jesus, P. V., I. Hausmanowa-Petrusewicz, R. I. Barchi. The effect of cold on nerve conduction of human slow and fast nerve fibres.- Neurology, 23, 1973, No 11, 1182-1189.

5. Dioszeghy, P., E. Stålberg. Changes in motor and sensory nerve conduction parameters with temperature in normal and diseased nerve.Electroencephalogr. Clin. Neurophysiol., 85, 1992, No 4, 229-235.

6. FitzHugh, R. Computation of impulse initiation and salutatory conduction in a myelinated nerve fiber.- Biophys. J., 2, 1962, No 1, 11-21.

7. Frankenhaeuser, B., L. E. Moore. The specificity of the initial current in myelinated nerve fibres of Xenopus leavis. Voltage clamp experiments.- J. Physiol. (London), 169, 1963, 438-444.

8. Frankenhaeuser, B., L. E. Moore. The effect of temperature on the sodium and potassium permeability change in myelinated nerve fibres of Xenopus laevis.- J. Physiol. (London), 169, 1963, 431-437. 
9. Fransses, H., G. H. Wieneke, J. H. Wokke. The influence of temperature on conduction block.Muscle Nerve, 22, 1999, No 2, 166-173.

10. Geerlings, A. H. C., K. Mechelse. Temperature and nerve conduction velocity, some practical problems.- Electromyogr. Clin. Neurophysiol., 25, 1985, No 4, 253-260.

11. Goldman, L., J. S. Albus. Computation of impulse conduction in myelinated fibers. Theoretical basis of the velocity-diameter relation.- Biophys. J., 8, 1968, No 5, 596-607.

12. Hardy, W. L. Propagation speed in myelinated nerve. II. Theoretical dependence on external $\mathrm{Na}^{+}$ and on temperature.- Biophys. J., 13, 1973, No 10, 1071-1089.

13. Hutchinson, N. A., Z. J. Koles, R. S. Smith. Conduction velocity in myelinated nerve fibres of Xenopus laevis.- J. Physiol. (London), 208, 1970, No 2, 279-289.

14. Johnson, E. W., K. J. Olsen. Clinical value of motor nerve conduction velocity determination.- J. Am. Med. Assoc., 172, 1960, 2030-2035.

15. Koles, Z. J., M. Rasminsky. A computer simulation of conduction in demyelinated nerve fibres.- $J$. Physiol. (London), 227, 1972, No 2, 351-364.

16. Lang, A. H., A. Puusa. Dual influence of temperature on compound nerve action potential.J. Neurol. Sci., 51, 1981, No 1, 81-88.

17. Lowitzsch, K., H. C. Hopf, J. Galland. Changes of sensory conduction velocity and refractory periods with decreasing tissue temperature in man.- J. Neurol., 216, 1977, No 3, 181-188.

18. Moore, J. W., S. W. Joyner, M. H. Brill, S. G. Waxman, M. Najar-Joa. Simulations of conduction in uniform myelinated fibres. Relative sensitivity to changes in nodal and internodal parameters.- Biophys. J., 21, 1978, No 2, 147-160.
19. Ritchie, J. M., D. Stagg. A note on the effect of potassium conductance (gk) on conduction velocity in myelinated fibers.- J. Physiol. (London), 328, 1982, 32-33.

20. Schwarz, J. R., W. Vogel. Potassium inactivation in single myelinated nerve fibres of Xenopus leavis.Pflügers Arch., 330, 1971, No 1, 61-73.

21. Schwarz, J. R., G. Eikhof. Na currents and action potentials in rat myelinated nerve fibres at 20 and $37^{\circ}$ C.- Pflügers Arch., 409, 1987, No 6, 569-577.

22. Schwarz, J. R., G. Reid, H. Bostock. Action potentials and membrane currents in the human node of Ranvier.- Pflügers Arch., 430, 1995, No 2, 283-292.

23. Stephanova, D. I. The effect of temperature on a simulated systematically paranodally demyelinated nerve fiber.- Biol. Cybern., 60, 1988, No 1, 73-77.

24. Stephanova, D. I. Model investigations of the temperature dependence of demyelinated and reorganized axonal membrane.- Biol. Cybern., 60, 1989, No 6, 439-443.

25. Stephanova, D. I. Myelin as longitudinal conductor: a multi-layered model of the myelinated human motor nerve fibre.- Biol. Cybern., 84, 2001, No 4, 301-308.

26. Stephanova, D. I., B. Dimitrov. Models and methods for investigation of the human motor nerve fibre.- In: Computational neuroscience: simulated demyelinating neuropathies and neuronopathies. D. I., Stephanova, B. Dimitrov, eds., Boca Raton (USA), CRC Press, Taylor \& Francis Group, 2013, 18-32.

27. Swadlow, H. A. S. G. Waxman, T. G. Weyand. Effects of variations in temperature on impulse conduction along nonmyelinated axons in mammalian brain.- Exp. Neurol., 71, 1981, No 2, 383-389. 